\title{
Honokiol Is a Potential Therapeutic Agent and Has a Synergistic Effect With 5-FU in Human Urothelial Cell Carcinoma Cells
}

\author{
MING-YANG LEE ${ }^{1,2}$, CHUNG-SHENG SHI $^{3}$, YEN-CHEN HSU ${ }^{4}$, KAO-JEAN HUANG $^{5}$, SHU-HSIN CHEN ${ }^{6}$, \\ PEI-WEN ZHAO ${ }^{6}$, HUI-CHEN CHUNG ${ }^{6}$, YUN-CHING HUANG ${ }^{4}$ and YING-RAY LEE ${ }^{2,6}$ \\ ${ }^{1}$ Department of Hematology and Oncology, Ditmanson Medical Foundation \\ Chiayi Christian Hospital, Chiayi, Taiwan, R.O.C.; \\ ${ }^{2}$ Department of Nursing, Min-Hwei College of Health Care Management, Tainan, Taiwan, R.O.C.; \\ ${ }^{3}$ Graduate Institute of Clinical Medical Sciences, Chang Gung University, Taoyuan, Taiwan, R.O.C.; \\ ${ }^{4}$ Division of Urology, Department of Surgery, Chang Gung Memorial Hospital, Chiayi, Taiwan, R.O.C., \\ ${ }^{5}$ Institute of Biologics, Development Center for Biotechnology, New Taipei City, Taiwan, R.O.C.; \\ ${ }^{6}$ Department of Medical Research, Ditmanson Medical Foundation \\ Chia-Yi Christian Hospital, Chiayi, Taiwan, R.O.C.
}

\begin{abstract}
Background/Aim: Honokiol is a biphenolic component of the bark of Magnolia, and has been shown to exert several activities, including anti-depressant, anti-emetic, anti-oxidative, anti-thrombotic, anti-angiogenesis, antianxiolytic, anti-inflammatory and anti-tumor effects. Materials and Methods: The anti-tumor activities of honokiol and its synergistic effect with 5-fluorouracil (5-FU) in human urothelial cell carcinoma (UCC) cells were investigated. Results: Honokiol significantly suppressed the proliferation of UCC cells in a dose- and time-dependent manner. Moreover, honokiol inhibited the tumorigenesis of UCC cells in vitro. In addition, honokiol induced cell cycle arrest at $G_{0} / G_{1}$ phase and caused apoptosis of UCC cells through the intrinsic pathway. Importantly, we demonstrated that honokiol potentiated the cytotoxic effect of 5-FU, and displayed a synergistic effect with 5-FU in UCC cells. Conclusion: Honokiol causes growth inhibition, tumorigenesis suppression, cell cycle arrest, apoptosis, and importantly has a synergistic
\end{abstract}

Correspondence to: Ying-Ray Lee, Ph.D., Department of Medical Research, Ditmanson Medical Foundation Chia-Yi Christian Hospital, 539 Zhongxiao Rd., Chiayi City 600, Taiwan, R.O.C. Tel: +886 52765041, Ext. 5560, Fax: +886 52765041, Ext.5555, e-mail: yingray.lee@gmail.com and Yun-Ching Huang, MD, Ph.D., Division of Urology, Department of Surgery, Chang Gung Memorial Hospital, No. 6 Sec. West, Chia-Pu Rd., Pu-Zi City, ChiaYi County, 613, Taiwan, R.O.C. Tel: +886 53621000 Ext. 2356 , Fax: +886 53623002, e-mail: chrishyc@gmail.com

Key Words: Honokiol, urothelial cell carcinoma, apoptosis, cell cycle arrest, synergistic effect. effect with 5-FU in human UCC cells. Therefore, this agent displays a therapeutic potential for treating human UCC.

Human bladder cancer is the second most common cancer of the genitourinary tract (1). The incidence ratio between males and females is approximately $3: 1$. The mortality of bladder cancer has increased in recent decades (1). More than $90 \%$ of bladder cancers are epithelial malignancies, with the majority being transitional cell carcinomas and about 5\% are adenocarcinomas or squamous cell carcinomas (2). Urothelial cell carcinoma (UCC) is a heterogeneous disease, and $70 \%$ of patients present with non-muscle invasive disease (Ta, $\mathrm{T} 1$ and carcinoma in situ), which tends to recur but is generally not life-threatening, whereas $30 \%$ of patients present with muscleinvasive disease, which is associated with a high mortality risk from distant metastases (3). Although transurethral resection by itself can eradicate a Ta, T1 tumor completely, these tumors commonly recur and can progress to muscle-invasive bladder cancers. The risk of progression of UCC patients after 5 years is $45 \%$ (4). Tumor metastasis is the primary cause of death in UCC, and is associated with a 5-year survival rate of approximately $8.1 \%$ (1). Once the cancer progresses to locally invasive disease (T2-T4), and/or regional or distant metastasis, survival is limited without treatment (5). To improve these unsatisfactory results, chemotherapy has been used to prevent local recurrence. The most commonly used approach is intravesical instillation, whereby the agents are instilled into the bladder to delay and prevent tumor recurrence $(6,7)$. However, current treatments have limited effect on human UCCs. In addition, although the United States Food and Drug Administration (FDA) has approved 126 oncological 
medications from 2006 to 2015, none has been approved for the treatment of UCCs (8). Therefore, an effective and novel treatment modality is urgently needed for UCCs.

Chinese herbal medicines have been extensively used in clinical practice for thousands of years in Asian countries. Magnolia officinalis, also named Houpo in Chinese or Saibokutu in Japanese, is an important herb in traditional Chinese and Japanese medicine for treating conditions such as neuronal disorders, anxiety, gastrointestinal disorders, thrombotic stroke, typhoid fever, and allergic disease (9). M. officinalis has been reported to contain a diverse group of biologically active compounds, including magnolol, honokiol, 4-Omethylhonokiol, obovatol, and other neolignan compounds (10). Magnolol and honokiol are the two major secondary metabolites found in ethanolic extracts of Chinese $M$. officinalis (9). Honokiol, a biphenolic bioactive component, has exhibited multiple biological activities, including anti-oxidant, antiinflammatory, anti-bacterial, anti-fungal, anti-virus, anti-cancer, pro-apoptotic, and anti-osteoclastogenic activities (11-15). The anti-tumor activity of honokiol has been shown in various tumors in humans, including neuroblastoma, glioblastoma, thyroid cancer, lung cancer, breast cancer, hepatoma, colon cancer, prostate cancer, bladder cancer, pancreatic cancer, gastric cancer, ovarian cancer, melanoma, and lymphoma (1319). Growth inhibition, cell cycle regulation and apoptosis induction are exhibited in honokiol-mediated tumor suppression in various human cancers $(13,16,19)$. Moreover, multiple pathways including NF-kB activation, reactive oxygen species (ROS) production, endoplasmic reticulum (ER) stress, extracellular signal-regulated kinases (ERKs), JNK, p38 pathways, RhoA/ROCK (Rho-associated protein kinase), csrc/JAK/STAT3, and protein kinase B (AKT)/mTOR signaling pathways have been demonstrated to influence honokiolmediated cellular death or tumor migration (16).

In addition, 5-fluorouracil (5-FU) is a pyrimidine analog that is widely used in the treatment of various solid cancers, including human urothelial carcinoma $(20,21)$. When it enters cancer cells, it is converted into three active metabolites including fluorodeoxyuridine monophosphate (FdUMP), fluorodeoxyuridine triphosphate (FdUTP) and fluorouridine triphosphate (FUTP), which disrupt the action of thymidylate synthase and exert cytotoxic effects by incorporating into RNA and DNA (21). Ultimately, these activities lead to the induction of apoptosis.

Furthermore, it has been reported that honokiol exerts anti-UCC activities through the induction of mitochondriamediated apoptosis (22). However, it is still unclear whether honokiol can influence the anti-UCCs activity of 5-FU. In the present study, we verified the anti-tumor effects of honokiol alone or in combination with 5-FU in human UCC cells by determining its effect on cell growth, tumorigenesis, cell cycle regulation and apoptosis. Our data demonstrated that honokiol is an effective therapeutic agent for treating human UCC, and most importantly it exerts a synergistic anti- UCC activity in combination with 5-FU.

\section{Materials and Methods}

Urothelial cell carcinoma cell lines and cell culture. The two human UCC cell lines, 5637 and HT1197, and SV-HUC-1 cells (a SV40 immortalized human uroepithelial cell line) were obtained from the Bioresource Collection and Research Center (BCRC, Hsinchu, Taiwan) (23, 24). 5637, HT1197 and SV-HUC-1 cells were maintained in minimum essential medium (MEM) (Gibco BRL, Grand Island, NY, USA), RPMI1640 medium (Gibco) and Ham's F12 medium (Gibco) with $10 \%$ FBS (Gibco), respectively, and were cultured at $37^{\circ} \mathrm{C}$ in a $5 \% \mathrm{CO}_{2}$ atmosphere according to BCRC's recommendations. 5637 cells were derived from a patient with grade II UCC, who was PIK3CA, FGFR3 wildtype and TERT and TP53 mutant. H1197 cells were generated from a patient with grade IV UCC, who was TP53 wildtype, and carried mutations in PIK3CA, FGFR3, and TERT.

Cell proliferation assay. Human UCC cells $\left(5 \times 10^{3} /\right.$ well $)$ were seeded in 96-well culture plates and incubated with medium only (containing $0.01 \% \mathrm{DMSO}$ as the negative control) or with medium containing various concentrations of honokiol (Sigma, St. Louis, MO, USA) or 5-FU (Sigma). Then, cell viability was examined by the Cell Counting Kit-8 (CCK-8) (Sigma) (25). Moreover, Z-VADfmk (BioVision, Mountain View, CA, USA), a pan-caspase inhibitor, was used to block caspase activation, and evaluate the effect of honokiol or honokiol in combination with 5-FU on apoptosis of UCC cells using CCK-8 analysis (19, 26-29).

Colony formation assay. To determine the effect of honokiol on in vitro tumorigenesis, UCC cells (600 cells/well) were plated in a 6well culture dish and pre-incubated with or without honokiol for 72 $\mathrm{h}$. Then, cells were grown for 14 days to form colonies, and the colonies were stained with crystal violet for further counting $(24,26)$.

Cell cycle analysis. Cells $\left(1 \times 10^{5}\right.$ cells/plate $)$ were seeded and then starved in serum-free medium for synchronizing cell cycle progression. After starvation, cells were incubated with DMSO or various concentrations of honokiol and/or 5-FU at different time intervals. Cells were then harvested and fixed with $70 \%$ methanol at $4{ }^{\circ}$ Covernight. Fixed cells were further incubated with RNase (10 $\mathrm{mg} / \mathrm{ml}$; Sigma) and propidium iodide (PI; $1 \mathrm{mg} / \mathrm{ml}$; Sigma) at room temperature (RT) in the dark for $30 \mathrm{~min}$. DNA content was determined by FACScan (Becton- Dickinson, San Diego, CA, USA) with the ModFit LT 3.3 software $(19,30)$.

Apoptosis analysis. Cells $\left(1 \times 10^{6}\right)$ were treated without or with honokiol and/or 5-FU. After incubation, cells were incubated with FITC-labelled annexin-V and PI (Sigma) for $15 \mathrm{~min}$ at RT, and the intensity of annexin-V or PI fluorescence was analyzed by FACScan (BectonDickinson). In addition, the mechanism underlying honokiol-mediated apoptosis was examined by western blotting with specific antibodies against the activation/cleavage of caspase- 9 and -3 (Cell Signaling, Danvers, MA, USA), and PARP (Cell Signaling) (13, 19, 27-29, 31, 32).

Statistical analysis. Data are presented as mean \pm standard deviation. Significance of differences was analyzed by one-way ANOVA and Fisher's least significant difference test. Statistical significance was defined as $p<0.05$. 

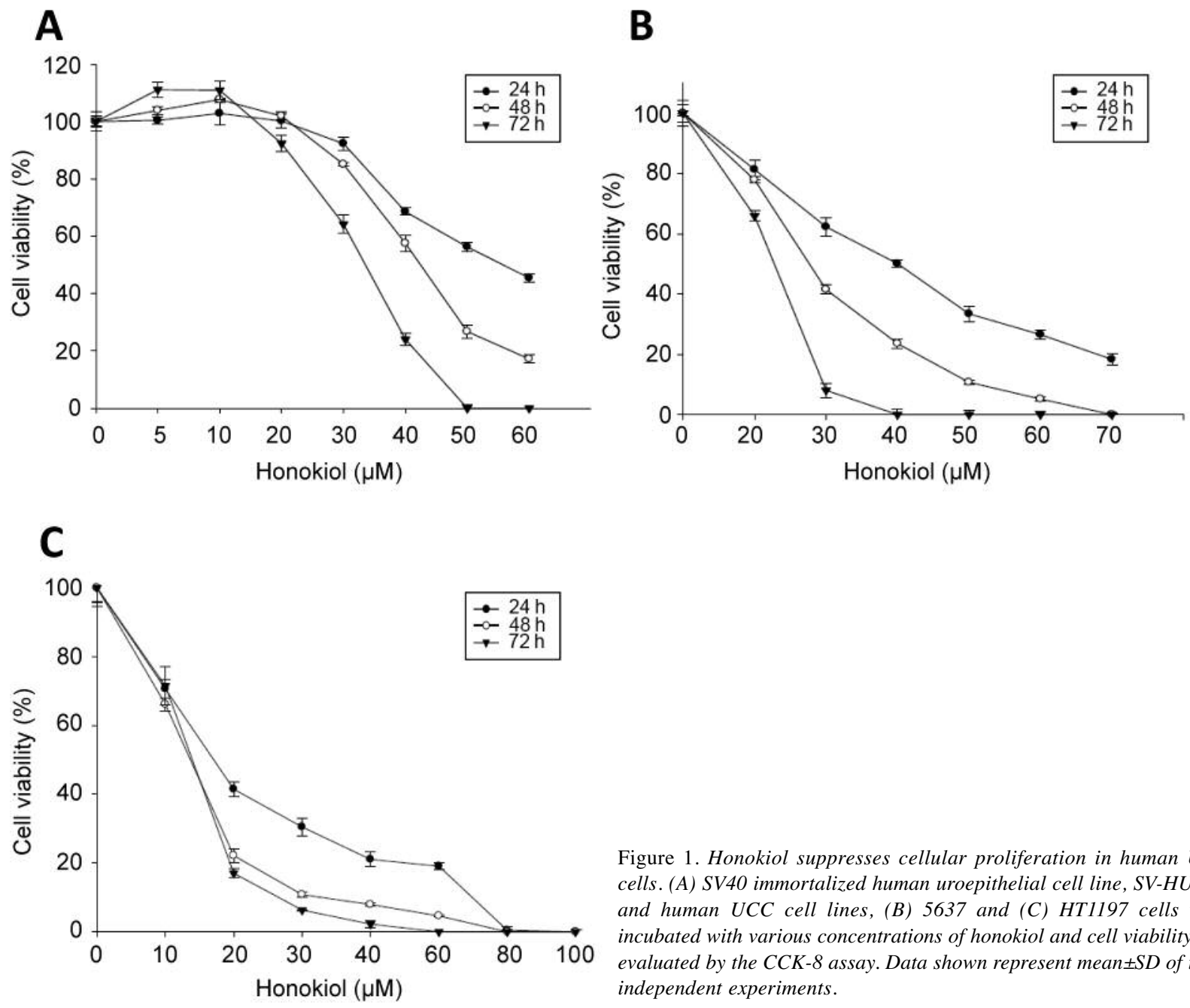

Figure 1. Honokiol suppresses cellular proliferation in human UCC cells. (A) SV40 immortalized human uroepithelial cell line, SV-HUC-1, and human UCC cell lines, (B) 5637 and (C) HT1197 cells were incubated with various concentrations of honokiol and cell viability was evaluated by the CCK-8 assay. Data shown represent mean $\pm S D$ of three independent experiments.

\section{Results}

Honokiol inhibited cellular proliferation and colony formation capacity of human UCC cells. To determine the anti-tumor activity of honokiol on UCC cells, SV-HUC-1, 5637 and HT1197 cells were incubated with DMSO (as a negative control) or various concentrations of honokiol. CCK-8 assay was performed to evaluate the effects of honokiol on cell viability. Our data showed that honokiol suppressed the proliferation of all cells in a time- and dose-dependent manner (Figure 1). The half maximal inhibitory concentration $\left(\mathrm{IC}_{50}\right)$ of honokiol in SV-HUC-1 cells was 54.5, 42.3, and $32.5 \mu \mathrm{M}$ at 24,48 and $72 \mathrm{~h}$, respectively. In addition, the $\mathrm{IC}_{50}$ in 5637 cells was $37.8,28.2$, and $22.6 \mu \mathrm{M}$ at 24,48 and $72 \mathrm{~h}$, respectively. Furthermore, the $\mathrm{IC}_{50}$ in HT1197 ells was 17.3, 13.1 , and $12.5 \mu \mathrm{M}$ at 24,48 and $72 \mathrm{~h}$, respectively. These data demonstrated that honokiol can effectively inhibit the growth of UCC cell lines, and that HT1197 cells were more sensitive

to the treatment of honokiol (Figure 1). Importantly, SV-HUC1 cells were more resistant to honokiol treatment (Figure 1A). Because SV-HUC-1 cells are SV40 immortalized human uroepithelial cells, it can be considered as a benign cell line. Therefore, these data suggested that honokiol may be a safe chemotherapeutic agent in human UCCs. In addition, to determine the anti-tumorigenesis property of honokiol in 5637 and HT1197 cells, the colony formation assay was performed. Figures $2 \mathrm{~A}$ and $2 \mathrm{~B}$ demonstrate that honokiol suppresses tumorigenesis in a dose-dependent manner. However, 5637 cells were more sensitive to honokiol than HT1197 cells. Altogether, our results indicated that honokiol may be a useful and safe chemotherapeutic agent for treating human UCC.

Honokiol induced cell cycle arrest at $G_{0} / G_{1}$ phase. Because honokiol suppressed cellular proliferation in 5637 and HT1197 cells, we further examined its effect on cell cycle regulation. Figures $3 \mathrm{~A}$ and $3 \mathrm{~B}$ illustrate that honokiol 
A
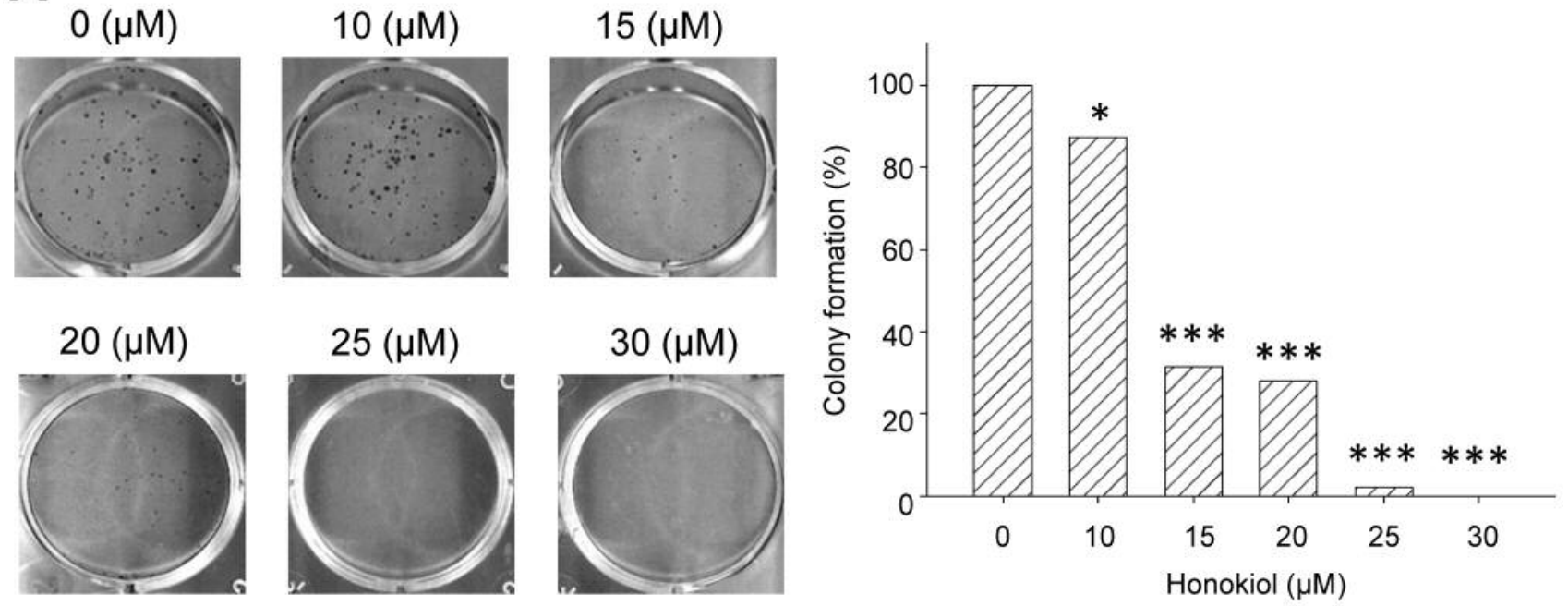

B
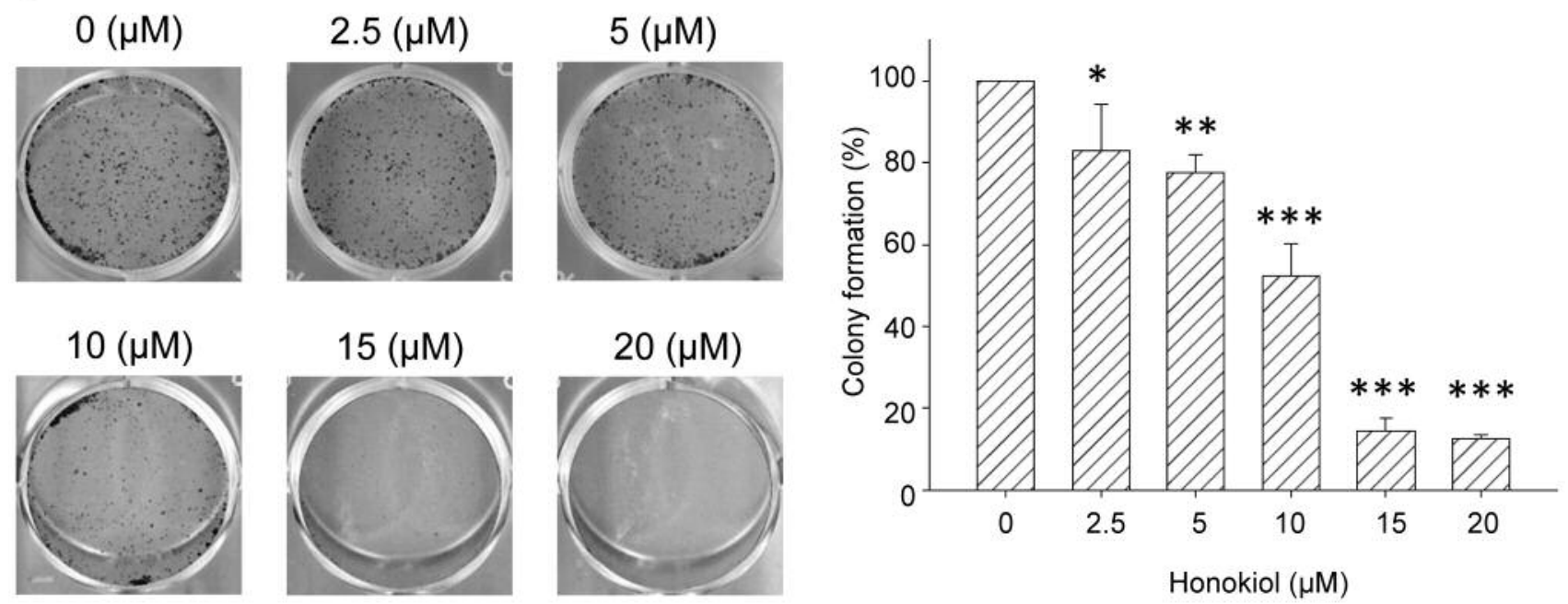

Figure 2. Honokiol reduces tumorigenesis in human UCC cells. (A) 5637 and (B) HT1197 cells were treated with honokiol and the formation of colonies was examined. Data shown represent mean $\pm S D(* p<0.05, * * p<0.01, * * * p<0.001)$ of three independent experiments.

causes cell cycle arrest at $\mathrm{G}_{0} / \mathrm{G}_{1}$ phase in 5637 and $\mathrm{HT} 1197$ cells in a dose-dependent manner at $24 \mathrm{~h}$ of treatment. Moreover, a significant increase in the percentage of cells in the sub-G1 phase was observed in both 5637 and HT1197 cells after honokiol treatment (Figure 3), suggesting that honokiol induces cell death after 48 and 72 $\mathrm{h}$ of treatment.

Honokiol regulated apoptosis in human UCC cells. To further investigate the effect of honokiol on apoptosis, 5637 and HT1197 cells were stained with annexin V and PI. The results showed that honokiol induced apoptosis in 5637 and
HT1197 cells after 48 and $72 \mathrm{~h}$ of treatment (Figure 4A and B). Furthermore, the underlying molecular mechanism of honokiol-mediated apoptosis in UCC cells was explored by western blotting, by examining the expression of caspases. Figures $4 \mathrm{~A}$ and $4 \mathrm{~B}$ show that honokiol increased cleavage of caspases-9, and -3 and PARP. In contrast, caspase- 8 was not activated in both 5637 and HT1197 cells under honokiol treatment (data not shown). These results suggest that the intrinsic pathway is involved in the honokiol-mediated apoptosis in human UCC cells.

To confirm the role of caspases in honokiol-mediated anti-UCC effect, Z-VAD-FMK, a pan-caspase-inhibitor, was 

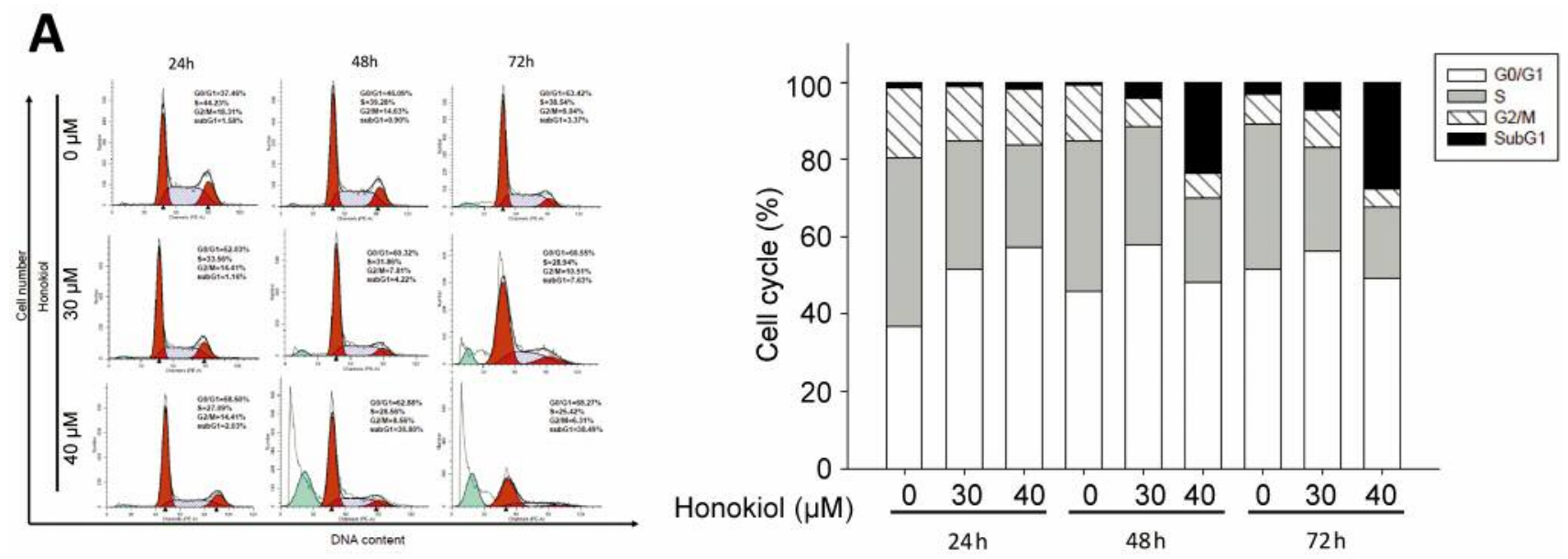

\section{B}
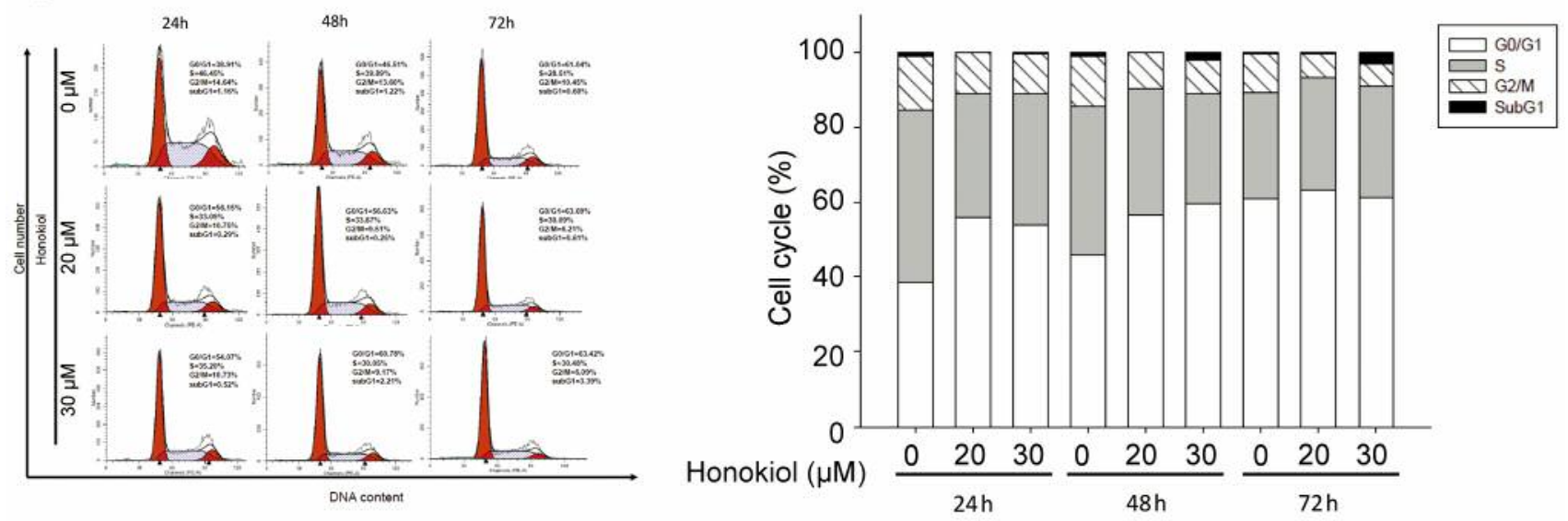

Figure 3. Honokiol treatment induces cell cycle modulation in human UCC cells. (A) 5637 and (B) HT1197 cells were incubated with honokiol and the cell cycle was examined by flow cytometry at 24,48 and $72 \mathrm{~h}$ post-treatment.

used. The levels of uncleaved caspase-3 and PARP were increased after treatment with Z-VAD-FMK in both 5637 and HT1197 cells following honokiol treatment (Figure 5A). Moreover, expression of the cleaved forms of caspase- 3 and PARP was reduced in cells incubated with Z-VAK-FMK and honokiol, compared to cells incubated with honokiol only (Figure 5A and 5B). Most importantly, the effect on cell viability was significantly reversed following treatment of 5637 and HT1197 cells with the combination of honokiol and Z-VAD-FMK (Figures 5A and 5B), suggesting that honokiol induced caspase-dependent apoptosis. Because the combination treatment of honokiol with Z-VAD-FMK was not able to cause a complete reversal of honokiol-mediated apoptosis, the existence of caspase-independent apoptosis cannot be rule out.
Honokiol exhibited synergistic anti-human UCCs activity with 5-fluorouracil. Previous studies have demonstrated that honokiol has an anti-cancer activity in various human cancer and UCC cells. Here, we further evaluated the therapeutic potency of honokiol and that of the clinical chemotherapeutic agent 5-Fluorouracil (5-FU), a common chemotherapeutic agent used to treat several human cancers. We therefore compared the anti-tumor activity of honokiol and that of 5FU in 5637 cells after treatment for $24 \mathrm{~h}$. The $\mathrm{EC}_{50}$ of honokiol in 5637 cells was $37.8 \mu \mathrm{M}$ after $24 \mathrm{~h}$ treatment, and $128.38 \mu \mathrm{M}$ in the 5-FU treated group (Data not shown). These data suggested that 5637 cells were more sensitive to treatment with honokiol than 5-FU. To address whether honokiol can modulate 5-FU-mediated anti-human UCC activity, human UCC cells were treated for 24 or $48 \mathrm{~h}$ with 
honokiol and/or 5-FU. Our results indicated that $40 \mu \mathrm{M}$ honokiol had a similar effect with $100 \mu \mathrm{M}$ 5-FU regarding cell growth suppression (Figure 6A). Importantly, a synergistic effect was determined following treatment of 5637 cells with both honokiol and 5-FU (Figure 6A). Further study illustrated that the 5-FU mediated anti-tumorigenesis activity could be enhanced at honokiol dose that does not inhibit colony formation (Figure 6B), suggesting their synergistic effect on anti-tumorigenesis in vitro in 5637 cells. In addition, apoptosis of 5637 cells was also observed following treatment with honokiol and 5-FU indicating their synergistic effect against human UCCs (Figure 6C and D). These findings demonstrate that honokiol in combination with 5-FU, can synergistically inhibit UCC proliferation, tumorigenesis and apoptosis and that honokiol is an alternative therapeutic agent for UCC.

\section{Discussion}

In the present study, we demonstrated an anti-tumor activity of honokiol in human UCC cells. Honokiol was able to inhibit proliferation, cause cell cycle arrest, induce apoptosis and suppress tumorigenesis. Most importantly, we also illustrated that honokiol enhanced the cytotoxicity of 5-FU, a clinical chemotherapeutic agent used for treating various cancer. The anti-cancer activity of honokiol has also been demonstrated in various cancers, including neuroblastoma, glioblastoma, thyroid cancer, lung cancer, breast cancer, hepatoma, colon cancer, prostate cancer, bladder cancer, pancreatic cancer, gastric cancer, ovarian cancer, melanoma, and lymphoma, in accordance with the findings of this study (13-19). It has also been reported that honokiol suppresses human bladder tumor growth and tumor stemness in vivo, accompanied by dysregulation of EZH2 and miR-143 expression (33). Moreover, honokiol has been shown to inhibit bladder cancer cell invasion by repressing SRC-3 expression and epithelial-mesenchymal transition (34). In addition, honokiol has been reported to induce apoptotic cell death through reactive oxygen species accumulation and mitochondrial hyperpolarization in bladder cancer cells (22). In addition, honokiol has exerted a synergistic effect with 5FU on apoptosis induction in oral squamous cell carcinoma cells (35). Here, it was also demonstrated that honokiol exerts a synergistic anti-tumor activity with 5-FU in human UCC cells. Our findings and those of others strongly suggest that honokiol whether used alone or in combination with conventional chemotherapeutics such as 5-FU can be a potential therapeutic agent for treating human UCC.

In addition, evaluation of novel therapeutic agents that have less toxicity in normal cells is an important and challenging task. Honokiol has been reported to be safe for in vitro and in vivo use (15). Moreover, a preparation containing honokiol has been used in preclinical models of asthma, and clinical trials are currently undergoing to test this in Japan $(36,37)$. This study suggests that honokiol is safe to use in humans.

Additionally, honokiol has been reported to act as an anticancer agent in human T-cell leukemia, hepatoma, glioblastoma, pleural mesothelioma, epidermoid squamous carcinoma, prostate cancer, thyroid cancer, bladder cancer, pancreatic cancer, oral cancer and breast cancer (13). We and others have demonstrated that honokiol induces apoptosis in human UCC and other cancers. Honokiol induces ROSmediated apoptosis through the intrinsic apoptosis pathway (BFTC-909 cells) (15). Here, induction of the extrinsicapoptotic pathway was observed in UCC cells after honokiol treatment (Figures 4 and 5). However, by blocking the activity of caspases with Z-VAD-FMK in 5637 and HT1197 cells, the effect of honokiol on the viability of 5637 cells was slightly reversed (Figure 5). These data suggest that in addition to caspase-dependent apoptosis, other death pathways (38) may play a key role in the honokiol-mediated anticancer effect in human UCC cells. Therefore, a comprehensive investigation of the anti-tumor activity of honokiol in all human UCC cell lines is recommended.

In addition, NF-kB, STAT3, EGFR, mTOR and MAPK have been reported to be therapeutic targets of honokiol (18). MAPK signaling through ERK, P38, and JNK as well as the $\mathrm{Akt} / \mathrm{mTOR}$ is known to be involved in cell differentiation, proliferation, and apoptosis. Moreover, activation of NF-kB as well as EGFR signaling is required to protect cancer cells from apoptotic cell death in certain advanced human bladder cancer cells and to increase the malignant potential of the disease $(18,39)$. Other studies have demonstrated that STAT3 promotes the progression from carcinoma in situ to invasive bladder cancer by increasing the expression of HIF1 $\alpha$ and VEGF (40). Also, the role of NF-kB, STAT3, EGFR, mTOR or MAPK pathways in honokiol-induced apoptosis should be further evaluated in UCC.

Honokiol and 5-FU have been shown to exert a synergistic effect both in vitro and in vivo on oral squamous cell carcinoma cells, and the intrinsic apoptotic pathway has been shown to be involved in this effect (35). 5-FU is known to exert cytotoxic effects via its incorporation into RNA and DNA, and has been shown to induce apoptosis that critically depended on the presence of p53 and the cleavage of BID $(35,41)$. Here, we demonstrated that honokiol could synergistically enhance the anti-proliferative and antitumorigenic actions of 5-FU (Figure 6). However, whether p53 and Bid are involved in the synergistic effect of honokiol and 5-FU in UCC needs further investigation.

In the present study, we demonstrated that treatment with honokiol inhibited cellular proliferation, tumorigenesis, cell cycle progression, and induced apoptosis in human UCC cells through the intrinsic pathway. The synergistic activity of honokiol with 5-FU was also illustrated in the present study. 

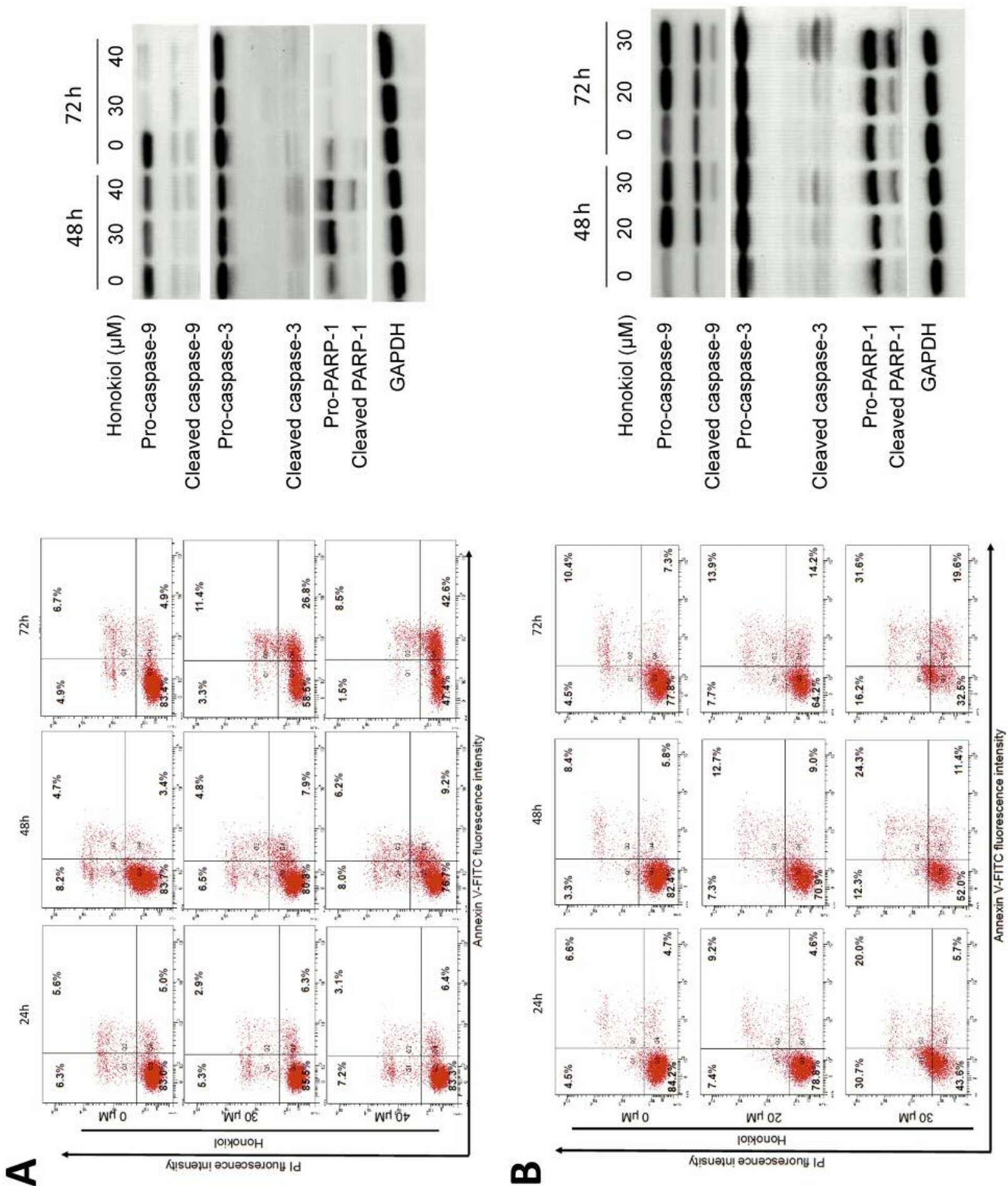


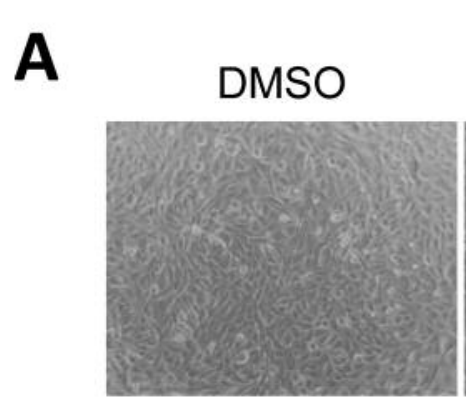

\section{Z-VAK-FMK}
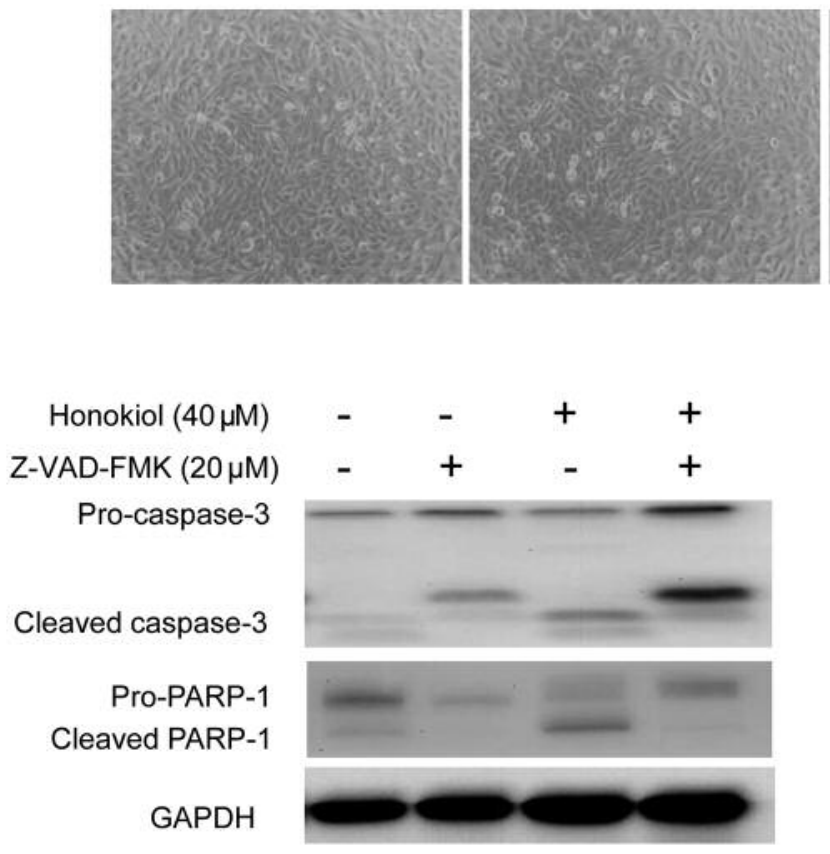

B
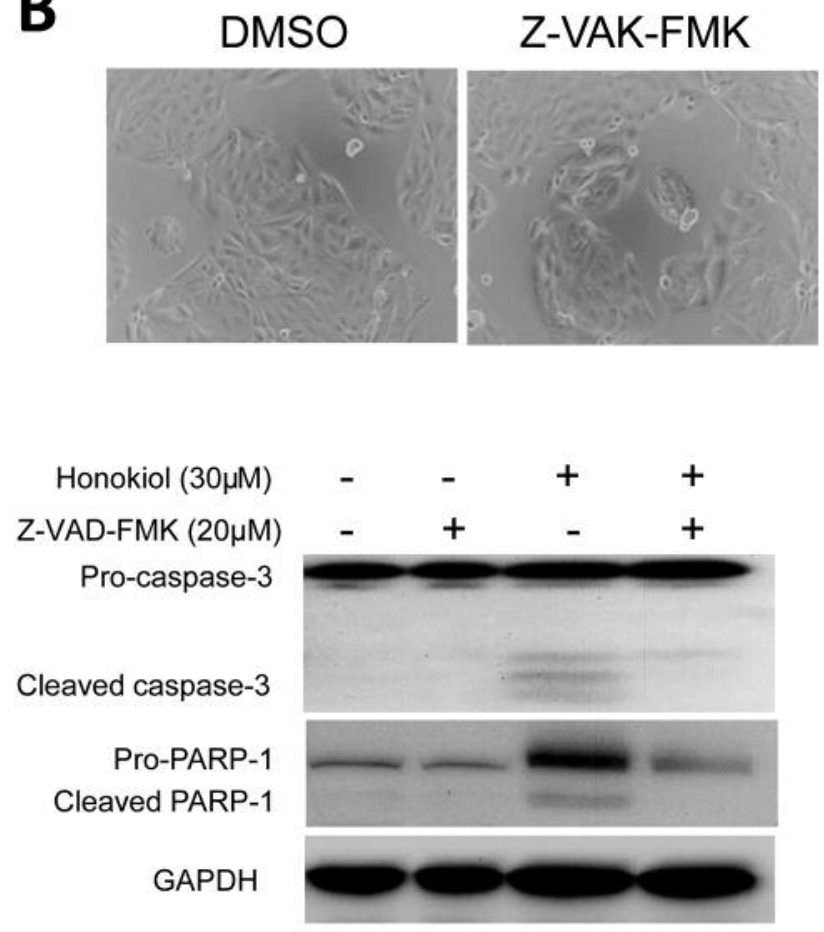

Honokiol + Z-VAK-FMK
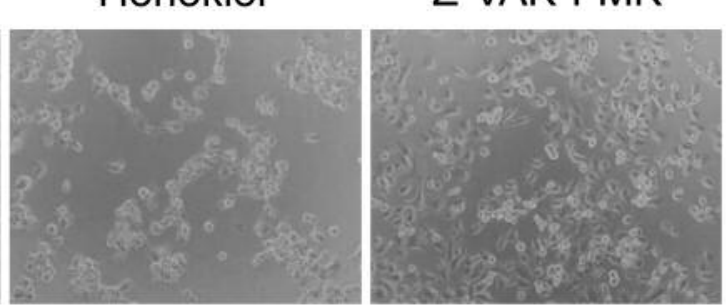

$* * *$

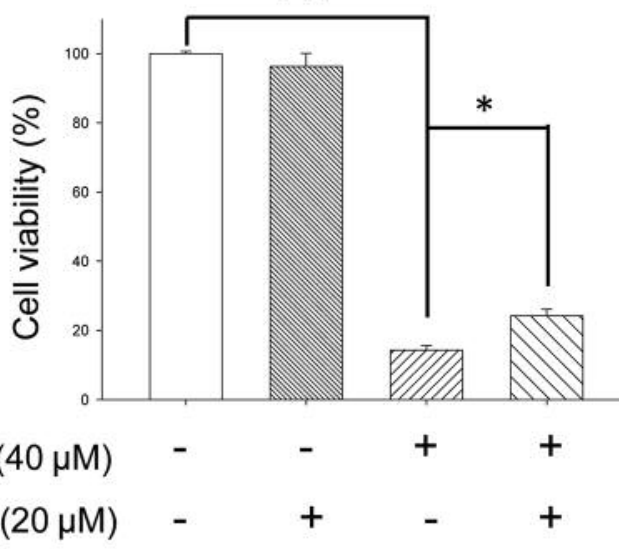

Honokiol + Z-VAK-FMK
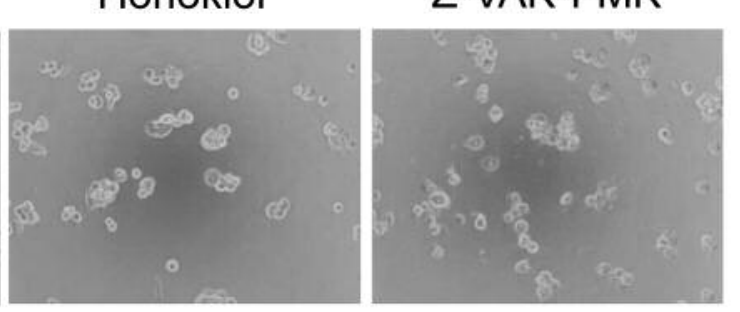

$* * *$

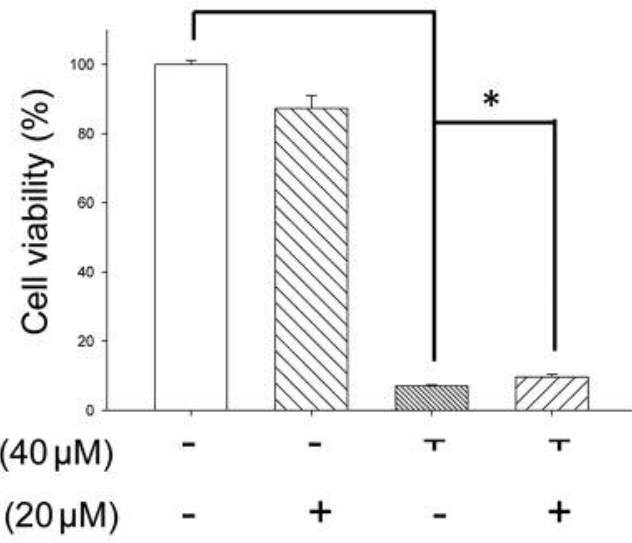

Figure 5. Blocking caspase activity increases cell survival under honokiol treatment. Honokiol-induced intrinsic apoptosis in human UCC cells was blocked with Z-VAD-FMK treatment. (A) 5637 and (B) HT1197 cells were treated with honokiol alone or in combination with Z-VAD-FMK for 48 $h$, and cellular morphology was determined under microscopy. The expression of caspase-3 and PARP was examined by western blotting. GAPDH was used as a loading control. Cell viability was determined with the CCK-8 assay. Data shown represent mean $\pm S D(* p<0.05$, **p<0.01, $* * * p<0.001)$ of three independent experiments. 

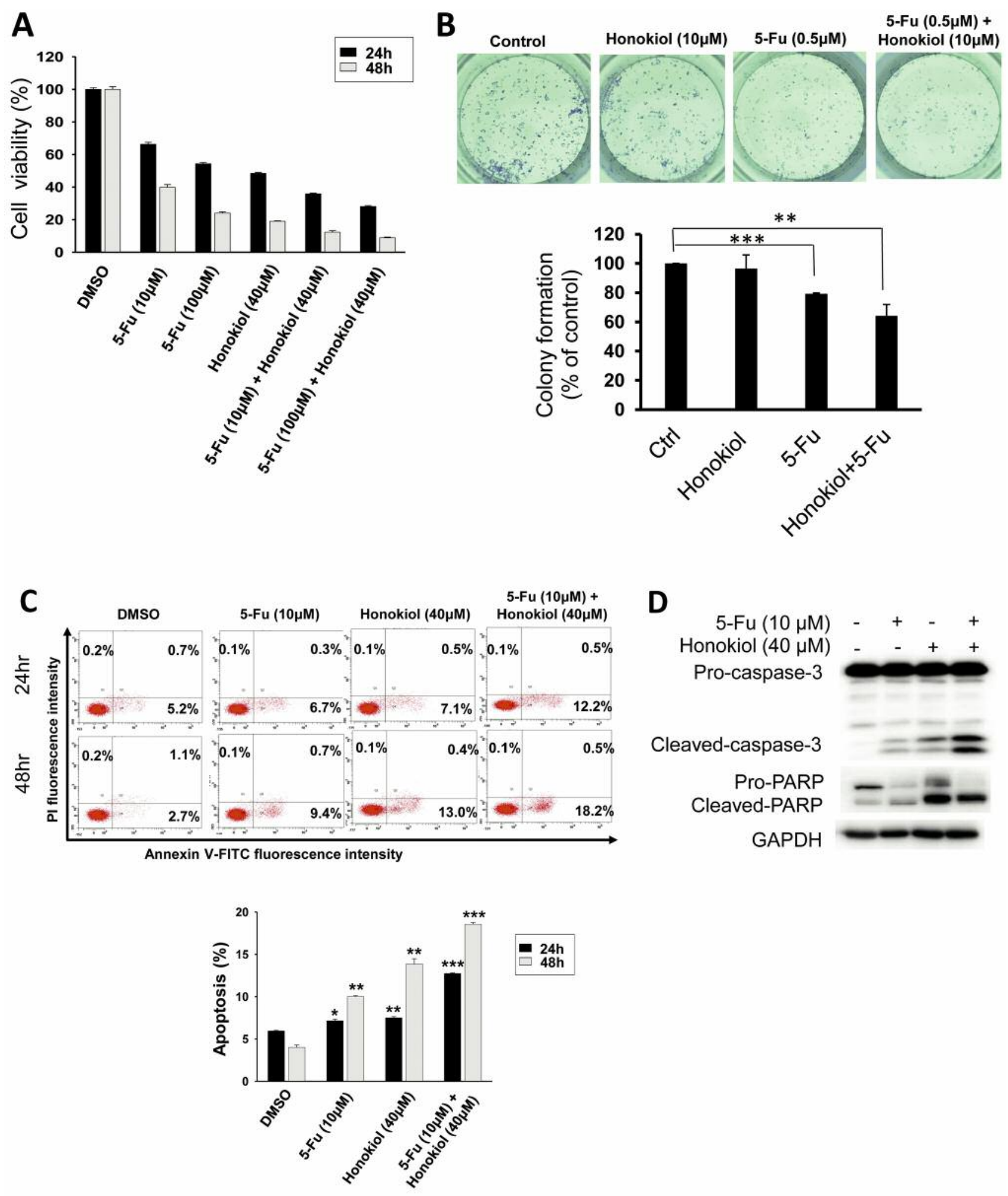

Figure 6. Honokiol and 5-FU exert a synergistic inhibitory effect on human UCC cell growth, tumorigenesis, and apoptosis induction. 8505c cells were incubated with honokiol, 5-FU or their combination, and the (A) cell viability was examined with the CCK-8 assay. (B) The colony formation assay was used to determine the in vitro tumorigenesis. (C) Cellular apoptosis was also determined with Flow cytometry and (D) was confirmed by western blotting after $48 \mathrm{~h}$ treatment. GAPDH was used as a loading control. DMSO was used as a negative control. Data shown represent mean $\pm S D(* p<0.05, * * p<0.01, * * * p<0.001)$ of three independent experiments. 
Therefore, administration of honokiol alone or in combination with 5-FU is a possible chemotherapeutic strategy for the treatment of UCC and warrants further investigation.

\section{Conflicts of Interest}

The Authors confirm that there are no conflicts of interest regarding this study.

\section{Authors' Contributions}

MYL, CSS YCH, KJH, YCH and YRL conceived and designed the experiments; YCH, KJH, SHC, PWZ, HCC and YRL analysed the data; MYL, CSS, YCH and YRL wrote the first draft of the manuscript; MYL, CSS, YCH, KJH, SHC, PWZ, HCC, YCH, and YRL read and confirm the criteria for authorship.

\section{Acknowledgements}

This study was supported by grants from the Ministry of Science and Technology of the Republic of China, Taiwan MOST 108-2314-B-705-001, Ditmanson Medical Foundation Chia-Yi Christian Hospital, Chiayi city, Taiwan (R106-39), and Chang Gung Memorial Hospital, Chaiyi, Taiwan (CMRPG6D0091 2). The Authors thank Mr. Myron for the critical reading of the manuscript.

\section{References}

1 Siegel RL, Miller KD and Jemal A: Cancer statistics, 2017. CA Cancer J Clin 67(1): 7-30, 2017. PMID: 28055103. DOI: $10.3322 /$ caac. 21387

2 Lopez-Beltran A: Bladder cancer: Clinical and pathological profile. Scand J Urol Nephrol Suppl 218: 95-109, 2008. PMID: 18815924. DOI: 10.1080/03008880802325226

3 Kaufman DS, Shipley WU and Feldman AS: Bladder cancer. Lancet 374(9685): 239-249, 2009. PMID: 19520422. DOI: 10.1016/S0140-6736(09)60491-8

4 Sylvester RJ, van der Meijden AP, Oosterlinck W, Witjes JA, Bouffioux C, Denis L, Newling DW and Kurth K: Predicting recurrence and progression in individual patients with stage ta t1 bladder cancer using eortc risk tables: A combined analysis of 2596 patients from seven eortc trials. Eur Urol 49(3): 466475; discussion 475-467, 2006. PMID: 16442208. DOI: 10.1016/j.eururo.2005.12.031

5 Faltas BM, Karir BS, Tagawa ST and Rosenberg JE: Novel molecular targets for urothelial carcinoma. Expert Opin Ther Targets 19(4): 515-525, 2015. PMID: 4406627. DOI: 10.1517/ 14728222.2014 .987662

6 Porter MP, Kerrigan MC, Donato BM and Ramsey SD: Patterns of use of systemic chemotherapy for medicare beneficiaries with urothelial bladder cancer. Urol Oncol 29(3): 252-258, 2011. PMID: 19450992. DOI: 10.1016/j.urolonc.2009.03.021

7 Shelley MD, Mason MD and Kynaston H: Intravesical therapy for superficial bladder cancer: A systematic review of randomised trials and meta-analyses. Cancer Treat Rev 36(3): 195-205, 2010. PMID: 20079574. DOI: 10.1016/j.ctrv.2009.12.005

8 Martin-Doyle W and Kwiatkowski DJ: Molecular biology of bladder cancer. Hematol Oncol Clin North Am 29(2): 191-203, vii, 2015. PMID: 4385194. DOI: 10.1016/j.hoc.2014.10.002

9 Chen YH, Lu MH, Guo DS, Zhai YY, Miao D, Yue JY, Yuan $\mathrm{CH}$, Zhao MM and An DR: Antifungal effect of magnolol and honokiol from magnolia officinalis on alternaria alternata causing tobacco brown spot. Molecules 24(11), 2019. PMID: 6600672. DOI: 10.3390/molecules24112140

10 Lee YJ, Lee YM, Lee CK, Jung JK, Han SB and Hong JT: Therapeutic applications of compounds in the magnolia family. Pharmacol Ther 130(2): 157-176, 2011. PMID: 21277893. DOI: 10.1016/j.pharmthera.2011.01.010

11 Fang CY, Chen SJ, Wu HN, Ping YH, Lin CY, Shiuan D, Chen CL, Lee YR and Huang KJ: Honokiol, a lignan biphenol derived from the magnolia tree, inhibits dengue virus type 2 infection. Viruses 7(9): 4894-4910, 2015. PMID: 4584296. DOI: 10.3390/v7092852

12 Lu CH, Chen SH, Chang YS, Liu YW, Wu JY, Lim YP, Yu HI and Lee YR: Honokiol, a potential therapeutic agent, induces cell cycle arrest and program cell death in vitro and in vivo in human thyroid cancer cells. Pharmacol Res 115: 288-298, 2017. PMID: 27940017. DOI: 10.1016/j.phrs.2016.11.038

13 Huang KJ, Kuo CH, Chen SH, Lin CY and Lee YR: Honokiol inhibits in vitro and in vivo growth of oral squamous cell carcinoma through induction of apoptosis, cell cycle arrest and autophagy. J Cell Mol Med 22(3): 1894-1908, 2018. PMID: 5824386. DOI: $10.1111 /$ jcmm. 13474

14 Chou HC, Lu CH, Su YC, Lin LH, Yu HI, Chuang HH, Tsai YT, Liao EC, Wei YS, Yang YT, Chien YA, Yu XR, Lee YR and Chan HL: Proteomic analysis of honokiol-induced cytotoxicity in thyroid cancer cells. Life Sci 207: 184-204, 2018. PMID: 29883720. DOI: $10.1016 /$ j.lfs.2018.06.002

15 Sarrica A, Kirika N, Romeo M, Salmona M and Diomede L: Safety and toxicology of magnolol and honokiol. Planta Med 84(16): 1151-1164, 2018. PMID: 29925102. DOI: 10.1055/a-0642-1966

16 Rauf A, Patel S, Imran M, Maalik A, Arshad MU, Saeed F, Mabkhot YN, Al-Showiman SS, Ahmad N and Elsharkawy E: Honokiol: An anticancer lignan. Biomed Pharmacother 107: 555-562, 2018. PMID: 30114639. DOI: 10.1016/j.biopha. 2018.08.054

17 Pan J, Lee Y, Wang Y and You M: Honokiol targets mitochondria to halt cancer progression and metastasis. Mol Nutr Food Res 60(6): 1383-1395, 2016. PMID: 27276215. DOI: 10.1002/mnfr.201501007

18 Arora S, Singh S, Piazza GA, Contreras CM, Panyam J and Singh AP: Honokiol: A novel natural agent for cancer prevention and therapy. Curr Mol Med 12(10): 1244-1252, 2012. PMID: 3663139. DOI: $10.1042 / \mathrm{bj} 2450119$

19 Lu CH, Chen SH, Chang YS, Liu YW, Wu JY, Lim YP, Yu HI and Lee YR: Honokiol, a potential therapeutic agent, induces cell cycle arrest and program cell death in vitro and in vivo in human thyroid cancer cells. Pharmacol Res 115: 288-298, 2016. PMID: 27940017. DOI: 10.1016/j.phrs.2016.11.038

20 Highley MS, Griffiths GO, Uscinska BM, Huddart RA, Barber JB, Parmar MK, Harper PG and Group NBCCS: A phase ii trial of continuous 5-fluorouracil in recurrent or metastatic transitional cell carcinoma of the urinary tract. Clin Oncol (R Coll Radiol) 21(5): 394-400, 2009. PMID: 19269798. DOI: 10.1016/j.clon.2009.01.011

21 Longley DB, Harkin DP and Johnston PG: 5-fluorouracil: Mechanisms of action and clinical strategies. Nat Rev Cancer 3(5): 330-338, 2003. PMID: 12724731. DOI: 10.1038/nrc1074 
22 Hsiao CH, Yao CJ, Lai GM, Lee LM, Whang-Peng J and Shih PH: Honokiol induces apoptotic cell death by oxidative burst and mitochondrial hyperpolarization of bladder cancer cells. Exp Ther Med 17(5): 4213-4222, 2019. PMID: 6447899. DOI: 10.3892/etm.2019.7419

23 Shen CH, Wu JD, Jou YC, Cheng MC, Lin CT, Chen PC, Tseng YS, Shi CS, Chen SY, Chang DC and Lee YR: The correlation between twist, e-cadherin, and beta-catenin in human bladder cancer. J BUON 16(4): 733-737, 2011. PMID: 22331730.

24 Shi CS, Li JM, Chin CC, Kuo YH, Lee YR and Huang YC: Evodiamine induces cell growth arrest, apoptosis and suppresses tumorigenesis in human urothelial cell carcinoma cells. Anticancer Res 37(3): 1149-1159, 2017. PMID: 28314276. DOI: 10.21873/anticanres. 11428

25 Chen SY, Liu GH, Chao WY, Shi CS, Lin CY, Lim YP, Lu CH, Lai PY, Chen HR and Lee YR: Piperlongumine suppresses proliferation of human oral squamous cell carcinoma through cell cycle arrest, apoptosis and senescence. Int J Mol Sci 17(4), 2016. PMID: 4849064. DOI: 10.3390/ijms17040616

$26 \mathrm{Lu}$ YC, Lee YR, Liao JD, Lin CY, Chen YY, Chen PT and Tseng YS: Reversine induced multinucleated cells, cell apoptosis and autophagy in human non-small cell lung cancer cells. PLoS One 11(7): e0158587, 2016. PMID: 4934785. DOI: 10.1371/journal. pone. 0158587

27 Hua SC, Chang TC, Chen HR, Lu CH, Liu YW, Chen SH, Yu HI, Chang YP and Lee YR: Reversine, a 2,6-disubstituted purine, as an anti-cancer agent in differentiated and undifferentiated thyroid cancer cells. Pharm Res 29(7): 1990-2005, 2012. PMID: 22477067. DOI: 10.1007/s11095-012-0727-3

28 Lee YR, Chen SH, Lin CY, Chao WY, Lim YP, Yu HI and Lu $\mathrm{CH}$ : In vitro antitumor activity of aloperine on human thyroid cancer cells through caspase-dependent apoptosis. Int J Mol Sci 19(1), 2018. PMID: 5796256. DOI: 10.3390/ijms 19010312

29 Lee MY, Li YZ, Huang KJ, Huang HC, Lin CY and Lee YR: Indirubin-3'-oxime suppresses human cholangiocarcinoma through cell-cycle arrest and apoptosis. Eur J Pharmacol 839: 57-65, 2018. PMID: 30267650. DOI: 10.1016/j.ejphar.2018.09.023

30 Li JM, Huang YC, Kuo YH, Cheng CC, Kuan FC, Chang SF, Lee YR, Chin CC and Shi CS: Flavopereirine suppresses the growth of colorectal cancer cells through p53 signaling dependence. Cancers (Basel) 11(7), 2019. PMID: 31336690. DOI: $10.3390 /$ cancers 11071034

31 Kuo CH, Lu YC, Tseng YS, Shi CS, Chen SH, Chen PT, Wu FL, Chang YP and Lee YR: Reversine induces cell cycle arrest, polyploidy, and apoptosis in human breast cancer cells. Breast Cancer 21(3): 358-369, 2014. PMID: 22926505. DOI: 10.1007/s12282-012-0400-z

32 Yeh HT, Tsai YS, Chen MS, Li YZ, Lin WC, Lee YR, Tseng YS and Sheu SM: Flavopereirine induces cell cycle arrest and apoptosis via the akt/p38 mapk/erk1/2 signaling pathway in human breast cancer cells. Eur J Pharmacol 863: 172658, 2019. PMID: 31518562. DOI: 10.1016/j.ejphar.2019.172658
33 Zhang Q, Zhao W, Ye C, Zhuang J, Chang C, Li Y, Huang X, Shen L, Li Y, Cui Y, Song J, Shen B, Eliaz I, Huang R, Ying H, Guo $\mathrm{H}$ and Yan J: Honokiol inhibits bladder tumor growth by suppressing ezh2/mir-143 axis. Oncotarget 6(35): 37335-37348, 2015. PMID: 4741933. DOI: $10.18632 /$ oncotarget.6135

34 Shen L, Zhang F, Huang R, Yan J and Shen B: Honokiol inhibits bladder cancer cell invasion through repressing src-3 expression and epithelial-mesenchymal transition. Oncol Lett 14(4): 42944300, 2017. PMID: 5604166. DOI: 10.3892/ol.2017.6665

35 Ji N, Jiang L, Deng P, Xu H, Chen F, Liu J, Li J, Liao G, Zeng X, Lin Y, Feng M, Li L and Chen Q: Synergistic effect of honokiol and 5-fluorouracil on apoptosis of oral squamous cell carcinoma cells. J Oral Pathol Med 46(3): 201-207, 2017. PMID: 27465776. DOI: 10.1111/jop.12481

$36 \mathrm{Ko} \mathrm{CH}$, Chen HH, Lin YR and Chan MH: Inhibition of smooth muscle contraction by magnolol and honokiol in porcine trachea. Planta Med 69(6): 532-536, 2003. PMID: 12865972. DOI: $10.1055 / \mathrm{s}-2003-40654$

37 Taniguchi C, Homma M, Takano O, Hirano T, Oka K, Aoyagi Y, Niitsuma T and Hayashi T: Pharmacological effects of urinary products obtained after treatment with saiboku-to, a herbal medicine for bronchial asthma, on type iv allergic reaction. Planta Med 66(7): 607-611, 2000. PMID: 11105563. DOI: $10.1055 / \mathrm{s}-2000-8626$

38 Lin MC, Lee YW, Tseng YY, Lin YW, Chen JT, Liu SH and Chen RM: Honokiol induces autophagic apoptosis in neuroblastoma cells through a p53-dependent pathway. Am J Chin Med 47(4): 895-912, 2019. PMID: 31091975. DOI: 10.1142/S0192415X19500472

39 Nicholson RI, Gee JM and Harper ME: Egfr and cancer prognosis. Eur J Cancer 37: S9-15, 2001. PMID: 11597399. DOI: $10.1016 / \mathrm{s} 0959-8049(01) 00231-3$

40 Santoni M, Conti A, Piva F, Massari F, Ciccarese C, Burattini L, Cheng L, Lopez-Beltran A, Scarpelli M, Santini D, Tortora G, Cascinu $S$ and Montironi R: Role of stat3 pathway in genitourinary tumors. Future Sci OA 1(3): FSO15, 2015. PMID: 5137995. DOI: $10.4155 /$ fso. 15.13

41 Sax JK, Fei P, Murphy ME, Bernhard E, Korsmeyer SJ and ElDeiry WS: Bid regulation by 53 contributes to chemosensitivity. Nat Cell Biol 4(11): 842-849, 2002. PMID: 12402042. DOI: $10.1038 / \mathrm{ncb} 866$
Received October 15, 2019

Revised October 30, 2019

Accepted October 31, 2019 